\title{
A Game Based Learning Approach to Enrich Special Education in Sri Lanka
}

\author{
Nadira T. Perera, Induni S. D. Wijerathne, Manori M. Wijesooriya, A. T. Dharmarathne, A. R. Weerasinghe
}

\begin{abstract}
In this fast moving world, providing equal access to information and knowledge to everybody is restricted due to specific groups of students who are not capable to engage in learning in a regular manner because of their physical, mental or psychological disabilities. These kinds of students require individual attention and special assistance from their parents and teachers in learning process. They might benefit from some other special learning techniques provided as learning aids rather than conventional learning methods. Since Information and Communication Technology (ICT) based learning is a novel approach which integrates learning with computing, this research is intended to explore the relevancy of ICT based education for enhancing the learning effectiveness of students with special needs. A few game based activities have been developed considering both functional and non-functional requirements, gathered through discussions had with doctors and teachers in special education. These activities focus on basic concepts of three subject areas as Colour, Number and Language. In order to evaluate the performance improvement, two tests were carried out as 'pre-test' and 'post-test' for a sample of students with the developed activities. Number of levels completed by each student, number of mistakes made during the game and time taken to finish a game were measured throughout the user evaluation phase. With this experiment, it was proven that ICT can be used as a driving tool to enhance the learning effectiveness in special education domain.
\end{abstract}

Index Terms - Autism, Down syndrome, ICT based education, Learning disabilities, Skill development, Special needs students

\section{INTRODUCTION}

The term 'Special Educational Needs' is characterized by a collection of physical and mental disorders which affect the learning of students regardless of their intellectual abilities. They suffer from several emotional and behavioural disorders, developmental disorders and communication challenges that make it difficult for them to access education [1][2]. In this research, the focus is on students with intellectual disabilities such as Autism Spectrum Disorder (ASD), Attention Deficit Hyperactivity Disorder (ADHD), Down syndrome, Auditory Processing Disorder and Cerebral Palsy.

In accordance with the present circumstances in Sri Lanka, there is a considerable number of students who are suffering from such disabilities and they are does not have even reading and writing abilities [3]. According to [4], there are 17 special

Manuscript received May, 02, 2014. Recommended by Dr. Hakim Usoof on June 25, 2014

Nadira T. Perera, Induni S. D. Wijerathne, Manori M. Wijesooriya, A. T. Dharmarathne, A. R. Weerasinghe are with the University of Colombo School of Computing, No. 35, Reid Avenue, Colombo 07, Sri Lanka (e-mail: nadiratharanga@gmail.com, ishadiwijerathne@gmail.com,

maduwijesooriya@gmail.com, atd@ucsc.lk, arw@ucsc.lk ) schools in Sri Lanka and the ratio of 'student to teacher' in government, private, and special schools is about 20:1. Although those students could be improved through a specialized education, majority of them are not given such an education due to many reasons including economic barriers, lack of proper facilities, and lack of specialized teachers.

ICT has leaped beyond boundaries, especially in the education sector by opening new paths to access knowledge and information. New forms of ICT based education systems have been emerged such as e-learning, game based learning, learning via virtual reality. Consequently, there is a possibility of applying ICT in special education. Most of the countries in the world are using ICT for special education in more effective and efficient ways [15], however, still it is in a very low state in Sri Lanka. Although there are some specialized software materials which have been developed by other countries, Sri Lankan students are unable to use them because of the language barriers.

Therefore, the primary objective of this research is to investigate the possibility of introducing ICT for special education in Sri Lanka and how effective it would be to the Sri Lankan society. Since ICT is still a new tendency for a country like Sri Lanka, it is necessary to have a proper background analysis and an investigation about the feasibility of ICT usage within the discipline of special education.

A game based learning approach is proposed through this research by developing number of computer based games and activities specially designed for students with special educational needs. These games have been developed covering three subject areas: Colour, Number and Language. In order to eliminate the language barrier, it was intended to develop games in Sinhala language.

The effectiveness of the proposed solution is analysed by conducting a pre-test and a post-test. The evaluation was based on the number of steps each student proceeded with, number of mistakes made and average time taken to complete a single step. In addition to that, the type of the disorder was taken in to consideration for the analysis.

In this paper, Section II summarizes a thorough investigation of previous efforts in using ICT to help those with special educational needs. Section III introduces the methodology carried out to introduce ICT based education in this research, while design considerations are discussed in section IV. Implementation and evaluation of proposed solution are included in section V and VI respectively. Next an analysis is done using the gathered data in section VII and finally conclusions are summarized while describing some possible future work related to this research in later sections. 


\section{RELATED WORK}

\section{A. Special Education in Sri Lankan Context}

In order to evaluate the current status and problems of teachers in special education, a survey has been carried out by the Department of Special Needs Education at the Open University of Sri Lanka [5]. Under their review assignment, eight aspects of education have been considered including curriculum design, content and skill development.

According to the Department of Special Needs Education of Open University of Sri Lanka, equal educational opportunities should be provided for all children in the country and therefore, giving educational opportunities for children with special educational needs is a responsibility of the whole society [5]. As mentioned in [5], when preparing learning modules, they are prepared first in English and then translated into Sinhala and Tamil. As a result, the translated modules become less comprehensive because the translations are done by people who do not know the subject.

\section{B. Based on Disability}

Many research papers have been published on methods of utilizing ICT to overcome the difficulties of the students with learning disorders. These students mostly lack the communicational and behavioural skills and slow in understanding what is taught in the classroom. The software "Learning to Shop" [6] assists the people with Autism Spectrum Disorder (ASD) to learn a shopping scenario. It consists of four stages including preparing the shopping list, preparation of the money needed with the use of a wallet, selection of the items in the list from the supermarket shelves, and the payment at the cashier.

The first level of this software facilitates photographs and videos for low-functioning users who can understand visual representation. Second level consists of pictures and animations while the third level is enriched with written words. Fourth level is designed for higher-functioning students who can read words and sentences. The importance of this software is that it can be adapted for students with ASD according to their level of disability. In fact, it is vital to have such a categorization in this type of software since all these students cannot be placed at the same level [7].

As most of these students lack behavioural skills, the suggested "visual schedules" [8] can be used to display planned activities using several symbols such as icons, images, photographs and actual objects. It helps students to understand the sequence of the steps of an activity. Because of having both visual cues and verbal cues, it is very valuable for students with special needs. Further, teachers use hardware devices to communicate with Autistic students [9].

It is acknowledged in [10] that people with communication difficulties could be assisted by using gestures, a non electronic communication board, or an electronic voiceoutput device. Personal support technologies, such as Personal Digital Assistants (PDAs) will be useful for learners with cognitive disabilities. Specialized PDA software which enables users to manage personal schedules is currently available.

In [11], Silva et al have focused only on the group who has Autism Spectrum Disorder (ASD) and identified the benefits of using ICT to develop the communicative competences of those students using a novel multimedia platform called TROCAS. Their focus on customizability is very important since this solution is for a special group of students, not for normal students. Ease of adaptability to the target group, ease of being used by students and teachers, portability, configurability and adaptability according to the degree of severity of the target group are some of the features of TROCAS.

This platform was designed to support photos, videos, audio and some more things as revealed on [11]. The message board is very useful since it helps these students to enhance their communication competences by exchanging their ideas. Further, it does not require a special knowledge regarding the use of the computer, since it can be managed as the standard operating system.

Alphasmart keyboard is a strategy for augmentative communication for autistic children which shows pictures for keys and output the spoken words when the child chooses a picture [12]. This will be more appropriate for autistic children to improve their communication skills through this aural aid.

It has been reported that dyslexics retain information more easily when more senses are involved in the learning process [13]. The use of ICT can motivate and encourage the dyslexic learners by creating visual, auditory and kinesthetic environment to improve subject specific concepts and selfesteem with less fatigue. According to [13], ICT usage offers the greatest independence in learning to all dyslexics, because of the speech recognition software. Even today, the speech recognition software is not matured to an acceptable level and at least normal students are not using that software because it requires an immense amount of prior training and a noiseless environment for better work.

Because of the inability to identify letters correctly at once, dyslexic students have to write the same word again and again. However, if they can type the piece of work, it removes the pressure of rewriting the same thing many times in order to generate a neat piece of writing [13]. Additionally, the font size, colour and line spacing can be changed accordingly to use in a comfortable way. Though pupils have extremely slow typing speed, practice will develop a greater speed soon. Again the author in [13] argues that handwriting of dyslexic pupils may deteriorate after the keyboard is introduced in.

\section{ICT Based Special Education}

According to the research "Preparing special education frontline professionals for a new teaching experience" [14], the key factor of using ICT for special education is not the technology itself, but the pedagogy used and the interaction between teacher, student and content. If the technology is used to support the acquisition of traditional skills, it will be a waste of time and technology. Therefore, both theoreticians and practitioners have to think in a different and innovative way to apply the technological advancement into the real context.

Further it is suggested that ICT can be used as a motivating factor rather than just using to communicate with the available knowledge because younger generation is very enthusiastic in new technological innovations. The students may easily be attracted to new educational environment and then they can be guided to the learning process indirectly. As a result of interacting with computers, the students will get more effective and efficient education than the traditional education. 
According to the analysis done by British Educational Communications and Technology Agency [15], ICT can be used to support the learning of students with special educational needs in UK. The technology can help these students to overcome many of their communicational difficulties. This analysis has covered several areas including communication aids, software and web accessibility, teacher training and support and connecting learning communities. By using special access devices to use the computers, the students with physical disorders will motivate for doing the same lesson again. As revealed by analysis in [15], ICT helps the students to communicate and learn more effectively. In addition, there are number of benefits for both teachers and parents [15].

Further, it is essential to keep the relationship between the gaming subject and the educational subject in order to enrich both the game skill and curriculum knowledge. The facility of repeat and try again is very useful because usually these students are learning through repetition [16].

Mainly the majority of special students are educated at normal schools. The inadequate resources in schools is one of the main problems and providing teachers' training on special education is emphasized [17]. Ghana has come up with many solutions that can address the problem of learning disabilities of these students. Content-rich software is the main software that they are using in classroom to assist these students. They have refrained from using American and British software as it is difficult for these students to adapt to them.

The attempt of conducting a teacher training program may add a value to this program because this may not succeed if teachers are not willing to adapt new technologies in to their teaching strategies [18]. Explaining the importance of ICT usage in special education and giving the hands-on experience for the teachers are worth in order to improve the usage of new technologies in education curriculum. Teachers were able to build the structure of the lesson according to the individualized learning even at group works. It lets students to build the self-confidence and independent learning skills under their own comfortable speed.

The findings of this study have showed that a classroom with technology has a motivational setting than a place without technology. Therefore, using ICT is worth since it is one of the successful motivation factors of learning. Students are able to try out tasks in different levels of the games, quizzes and they will be challenged in every level. It helps them to bear a challenge in their real lives.

The provided games will enhance the critical thinking power of students by aiming at winning the game, while forgetting they are learning through the computer. It is a good strategy for teaching, because the students may not be interested on those activities if they feel that they are learning. By gaining the competency with these games, students will experience a higher level of self-esteem when they get the chance to complete a task which they previously unable to achieve.

\section{Serious Games for Students with special needs}

The students tend to absorb new information when playing digital games. Self learning is one of the better ways of learning rather than teaching everything by a tutor. Since the students can engage with goal oriented tasks in both real world and non-real world scenarios, it aims to improve the attention, memory, behaviour, cognitive and motor skills [19].
The ability of personalization of the games is useful because it can be adapted according to their level of disability of each individual. Since these serious games deal with educational materials, the students can enhance their intellectual abilities while having fun. As stated in [9], serious games are a more effective way of learning. However, having a considerable difference between two subjects will be a burden for students and keeping cross disciplinary content is important for reducing the gap between subjects.

As mentioned in [20], when developing a serious game for autistic students, attention should be paid for the characteristics related to interaction with the game, other than studying the associated technologies. Further, it has mentioned that serious games for autism cover the subjects related to education, therapy for communication, psychomotor treatment and behaviour enhancement.

According to F. Shahbodin et al, Arshia et al's computer game based on digital story telling concept which supports autistic children of age between 9 and 14 years to practice the use of money. Additionally, it provides an understanding about the social behaviour while helping to experience the shopping [20].

When designing serious games for students with special educational needs, designing the user interfaces for maximum accessibility and usability is recommended to reduce the cognitive load placed on the user when using software [21]. With regard to that, the authors have emphasized the design guidelines such as importance of using graphics, animations, providing alternatives to text, and auditory output to uphold user commitment.

'Cheese Factory' is a serious game [21] designed for teaching basic mathematics such as percentages, fractions and decimals where students have to match the given shape against another one in the interface to produce a full 'cheese'. There were several speed levels and difficulty levels in that game to make it scalable for any student with special educational needs. Further, the user interfaces are simple, colours are matched with overall interface, and instructions are clear.

'My Appearance' [21] supports the students to understand everyday "morning duties" from getting up until leaving home including having a shower and the breakfast. The game has been developed using Flash and the graphic interfaces are clear and understandable. Finally, the students receive a feedback on their performance using sounds and subtitles.

\section{E. Effect of Human Computer Interaction}

Human Computer Interaction (HCI) has been considered as the main factor on developing applications for autistic students as they are more interactive with attraction [25]. As discussed below, the interfaces, colour combinations and other key features should be taken into careful consideration since these students are different to normal students.

It has been acknowledged that designing human-computer interfaces for students with physical disabilities is harder, because their abilities are dispensed in a larger range than able-bodied. Biswas [22] has introduced a simulator to evaluate the assistive interfaces which can predict the interaction patterns when using variety of input devices.

As mentioned in [23], there are several recommendations which should be accomplished when developing a system. Using graphics and icons, using clear, unambiguous text, 
simple screen layout, consistency, contrasting colours, and large, clear navigation buttons, descriptive hyperlinks, minimizing scrolling, limiting the number of fonts, and supporting text browsers are some of them. Graphics and icons will be more attractive than text because these students have difficulties in reading. Further, using large fonts, understandable buttons and clear and simple layout is recommended for eliminating ambiguity. The colour combination should also be considered. The headings, titles and appropriate prompts should be placed at the same place of each page to keep the consistency. The name of the user can be used for the username in the login page. It will be more convenient for them because memorizing an extra word or phrase as the username is not required.

It is better to use a natural voice of a person rather than using a synthesized voice. The assignment submission process can be done by providing the space to do the assignment at the same place in this e-learning system instead of changing the file format and attaching them. This type of system will help students to do their tasks without any supervision from a tutor.

\section{F. Virtual Environments}

Florian and Lani [25] mentioned that if students are suffering from severe learning disabilities, they could be provided with simulation and virtual environment to improve.

Adjustable Virtual Classroom [26] has mainly two components: "editor tool" and "viewer tool". The editor tool is for the teacher or parent to edit the settings of the virtual classroom. According to the modifications done in editor tool, the viewer tool displays the classroom to the student. As in Figure 1, the questions appear on the blackboard. The most important thing is the editor tool. One of the major advantages of this software is the ability to include the real faces on to the teacher and students' avatar faces. The other avatars, in addition to teachers' avatar are controlled by the software randomly.

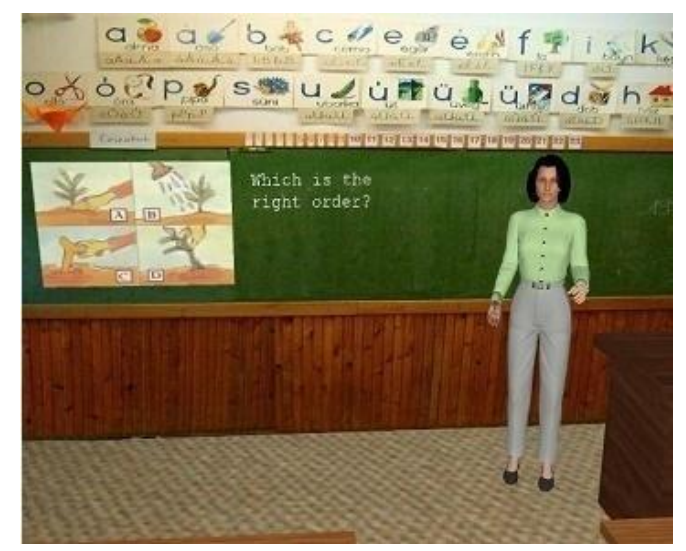

Fig. 1 An adjustable virtual classroom proposed by Konstantinidis et al [19]

Konstantinidis et al [27] have used an avatar to respond on activities with correct and incorrect answers. This is really important on developing activities including words, colours and other related things and responses are motivating factors for these students. They have tried to enhance teacher-child education process in their approach by providing several difficulty levels. Students are given images to select in a semi virtual environment. It uses an avatar to respond on activities with correct and incorrect answers respectively. Developing activities including words, colours and other related things as responses are also important when developing activities, since they are motivating factors students. With the information provided, this approach seems to be an effective solution for autistic students.

It has been acknowledged that the reaction of students with learning disabilities (especially adults) to the use of multimedia personal computer was extremely positive, and it was clear that the multimedia capability and modern software had considerable potential on those students [28].

\section{G. Special Software}

It has been acknowledged that interactive software is capable of keeping the concentration of people in relevant educational activities [29]. It is essential to include more graphics, sounds and more interactive activities when developing software for the users with learning disabilities.

There are professional resources, special needs software and assistive technologies such as;

1. Software and typing books for students with cerebral palsy, missing fingers, learning disabilities, dyslexia, visually impaired.

2. Learning solutions for classrooms and homes for kids

3. Accessibility software and text to speech software Further, word-processors, screen-reading software and problem-solving software packages still provide useful snapshots of ICT applications. However, the ICT itself also can create barriers. William's study cited in [30] concludes that the current use of ICT in education doesn't concern about people with learning difficulties.

Although ICT can be used for special educational needs, it will be useful only when it is specially designed for these types of students. Screen readers, spell checkers, word prediction, text to speech and speech recognition software are some of the examples. Further, accessible options built in to Microsoft products such as magnifier, narrator and on-screen keyboard are also useful as temporary methods of accessing computers.

According to [28], NORDIS educational software, written primarily for students with moderate/severe learning disability, is popular in schools and homes. Integrating the computer games and animations in to learning activities was the main aim of NORDIS software.

Thomson [13] argued, the programs that use robotic sounding (synthesized) speech can help pupils to determine the accuracy of their text. Since the special needs students cannot recognize at least the human voice well, recognizing a robotic voice is questionable. However, to improve the accuracy of the text, predictive programs can be used. Those software help to reduce keystrokes, save typing time and aid spelling by suggesting the regular words that the user is trying to type [13]. The programs such as Penfriend Xp, Co Writer and TEXThelp are some examples.

Williams [10] reported that most of the teachers in UK think it is better if students are searching the internet for information or images of interests. It may be impossible for the dyslexics because of their reading and spelling difficulties. As a solution, dyslexic students can be allowed to 'read' the web via a screen reading software. 


\section{METHODOLOGY}

Interviews and participant observations are useful in understanding the students, their disabilities and the traditional special education strategies. As the first phase, seven teachers in special education centres and government schools, a consultant and a doctor who is specialized in Autism were interviewed. Some classroom activities of several learning categories such as speech, mathematics and arts were monitored. While observing, we could experience the way of teaching a 15-year old male student and his ability of working with Microsoft Word, Excel and Paint.

For the convenience of the teaching process, the students with special needs are categorized in to three main levels as primary, intermediate and senior. The categorization is not based on the students' age, but on their ability of knowledge acquisition. Basically, colour, language and number skills of the students with special needs are addressed in their educational curriculum. Therefore, developing games covering those three main subject areas is required for the three main levels.

Three primary colours, red, yellow and blue, are the main targets of the colour games developed for the primary students. Regarding number concepts, only the numbers from one to nine are considered and those numbers has been simply introduced using the shape and the phonic of the particular number. Same game theories were applied to introduce basic letters in alphabet.

The same subject areas (Colour, Number, and Language) that used for primary students were applied for the secondary students also. In order to improve colour identification skills, the games have been developed using both primary colours and secondary colours. Giving activities only on secondary colours would badly affect on learning process of those students since there is a possibility of forgetting the primary colours that they have learnt earlier. The number games designed for the intermediate students will teach to map the shape of the number with real value of it and language games designed are aimed at simple words with two or three letters.

For the senior level students, instead of colour games, more games are created to introduce the basic shapes such as circle, square, and triangle. Gradually, the students will be taught to perform small calculations with the four basic mathematical operations (addition, subtraction, multiplication and division) through number games. To introduce sentences, different language games will be created for senior level students.

\section{A. Activity Designing}

1) Introductory Sessions: The introductory sessions or activities have been designed to introduce the colours, numbers, letters, and sentences. These introductory sessions are not interactive and the user can view them and learn without doing an exercise. Figure 2 shows colour introductory activity designed for primary level students. Similar, introductory activities are designed to introduce numbers and letters for those students. For an example, it illustrates how the shape of number ' 1 ' is mapping with the phonic of 'one' (as

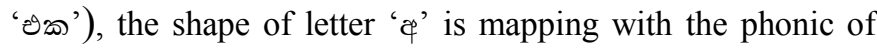

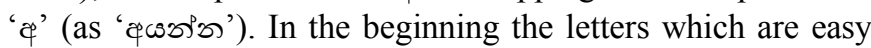
to write (ex. ఠ, O, ऽ etc) will be taught.

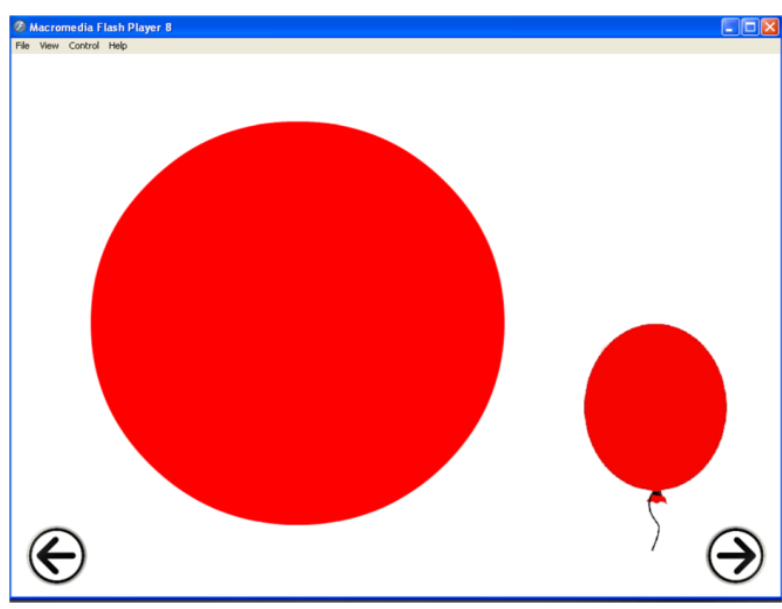

Fig. 2. Colour introduction of red colour for primary students

2) Games: The games can be used to practice the lessons learnt through the activities and traditional learning methods. In addition to that, the progress of the students' also can be evaluated by using these games. The games are more interactive and they will react on the users' responses on given activities. As an example if the user provides the correct answer for the given exercise it will send out a pleasant sound or an image of a happy face. An unpleasant sound or an image of an unhappy face will be the reaction for a wrong answer.

The activity showed in Fig. 3 is an example for a game. That aims at distinguishing primary colours and the final goal of that game is dragging the starts in to the cage of corresponding colour.

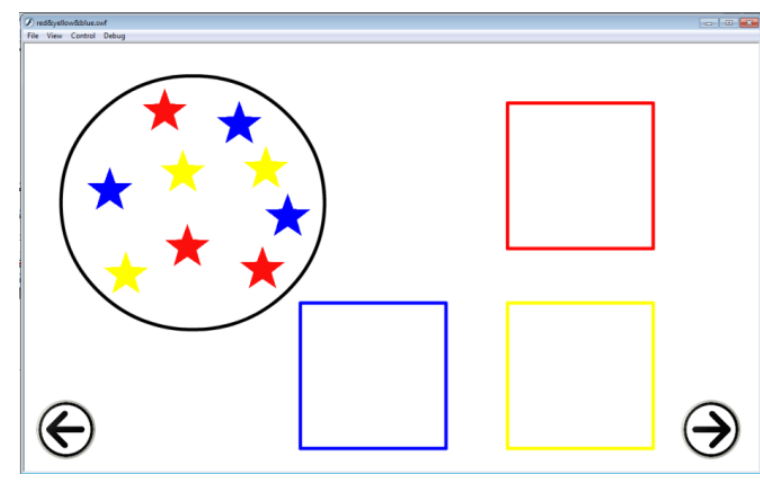

Fig. 3. A sample colour identification game for primary students

Further, some more interactive games are designed to practice the number and language skills. As an example, students are asked to build up some words by combining a set of given letters and afterwards to construct some small sentences by combining given words. The mathematical concepts will also be practiced by playing some games related to the mathematical calculation concepts.

Same as any other game, these games also should be designed in a way that the difficulty of the game is increasing gradually. The evaluation games (the games that used for evaluate the research) for colour, number and language have been developed considering many difficulty levels. In all of those levels, only abstract objects like circles, stars, balloons are used for easier understanding. 


\section{3) Tests}

Tests are collections of several random games for each level in each category (colour, number or language) covering all required subject matters. Once a student finishes the test, a parent or a teacher can check the time taken to finish that task.

\section{DESIGN CONSIDERATIONS}

As described in [30], referring to the study of Friedman \& Bryen, designing computer game interfaces for students in special education is totally different than designing such interfaces for normal students. They have recommended several design considerations that should be followed when designing systems for students with learning disabilities. Following are some of the design considerations used in practice when developing games for such students.

\section{A. Colour Combination of the Interface}

Colour is one of the most sensitive factors to be considered when designing interfaces [15]. When using colours in interfaces, applying only light colours and applying white background avoiding black, red and other dark colours are recommended. Using many colours within a single interface will confuse the students and there is a possibility of rejecting games with such interfaces.

Fig. 4 illustrates one of the activity interfaces developed to test how primary students recognize numbers. This has been developed according to the design considerations figured out during the early phases of research.

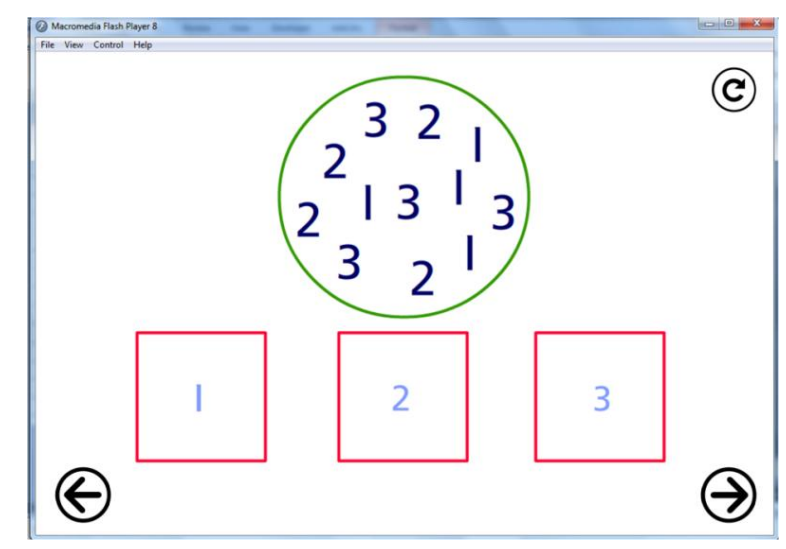

Fig. 4. Interface of number identification activity for primary students

\section{B. Complexity}

As mentioned in [15], the complexity of a game is a major concern when designing interfaces for students with special needs. The simpler it is, easier for them to understand. Using clear graphics and icons, unambiguous text, simple screen layout, consistency, contrasting colours, large and clear navigation buttons, descriptive hyperlinks, minimizing scrolling and limiting number of fonts are some of the recommendations to be attained in developing games for students with special needs [13]. Further, there should not be any feature that can confuse and scare them.

\section{Speed}

Games for students with special needs should be interactive, flexible and should be in an appropriate speed [15]. Since these students are very slow in their performance and response, this is a key factor to be addressed when designing games.

\section{Clear Audio}

In order to create a multi sensory learning environment, an auditory output also has been used for the activities and games. Therefore, it may help the students to capture information than just viewing through the computer screen and to keep their concentration on games. Basically, there are two kinds of audio clips that included in the activities and games.

1. Human voice

2. Audio clips to indicate correctness or incorrectness of the provided answer for a particular activity

Based on the recommendation of special education teachers, instructions were embedded in to the games as human voice, which were recorded with an adult female voice. It helps to eliminate the complexity of using instructions in textual format. In addition to that, another sound clip was used to indicate the end of the game while it serves as a reward for the student.

However, it is not recommended to include a sound clip as background music, because it will disturb the students' concentration.

\section{E. Graphics}

As mentioned in [15], images and animations support to increase the interactivity between the games and the student. Therefore, both images and animations have been used for the games as well as activities to make them more user-friendly. However, those images and animations should be simpler, clearer and familiar than the graphics used in games for ordinary students. Further, graphics can be used to reward the students when they finish the game successfully.

\section{F. Clear and Unambiguous Text}

The characteristics of text which is used for the games and activities of special students should be different from the characteristics of text used in games for ordinary students. The font size used in special educational games should be larger and they should be in same colour throughout the screen. Further, the instructions should be given in very simple terms in a clearly understandable manner such that, how it is spoken in day-to-day life.

However, it is not recommended to use text for the activities of primary level students. Because those students get distracted with letters and it will be a barrier to acquire the targeted knowledge from the activities and games.

\section{G. Simple Screen Layout}

A simple screen layout was maintained throughout the whole game because different layouts will loose the consistence of the sequence and it may distract the students' acquiring abilities of the subject content. Therefore, a single interface should be used with only the required changes in the interface without any additional things. As an example, when a child is playing a game, even navigation buttons should not be there on that screen. Those buttons will be displayed after the student finishes the game.

\section{H. Large Clear Navigation Buttons}

The navigation buttons should be large enough in size in order to facilitate the visibility. Further the buttons should be meaningful and visible clearly. 


\section{IMPLEMENTATION}

Implementation standards and best practices were followed in order to produce a better product and to reduce the probability of introducing errors in the application. During the implementation, the games were developed to improve the colour, number and language skills of the students with special educational needs. The development of each game/s for different categories is discussed below.

Macromedia Flash 8 and Adobe Flash CS4 were used with the help of Action Script 2.0 and Action Script 3.0 as development languages. Adobe Photoshop CS3 has been used as a supportive tool for editing the images used in the interfaces. The adult woman voice, which gives the instructions for the games, has been recorded, edited and optimized using Audacity 1.3. Further, Format Factory 2.10 was used to convert recorded voice clips and used sound clips into suitable file formats for maintaining quality of the developed games and games.

To execute these activities, Macromedia Flash Player 8 (or above) or any web browser with Shockwave Flash 10.3 (or above) as a plugin will be required. At the moment, the games can be played only using key board and mouse; however, they can be extended to play using special key boards and special mouse specifically designed for the children with special needs. Further, output sound devices (as speakers) are required to produce the instructions and other sounds of the games. Since these students can use only the primary hardware devices to interact with the computers, no advanced hardware devices are considered during implementation.

By combining all the games in colour, number and language skills, the final product was created as a collection of games. As it contains attractive and very simple interfaces to select appropriate games, even the students can handle it without the help of a teacher or a parent. All the interfaces are in Sinhala language and instructions also are given in Sinhala language.

In order to facilitate the usability of the final product, a user manual is provided which was written in Sinhala. All the instructions to access the games are explained so that the teachers or parents can assist students to enter into the game.

To introduce the product to the special education community in Sri Lanka, a compact disk (CD) was created including the final game. The game $\mathrm{CD}$ has been given to the teachers in some special education centres and for the parents of students in those centres. Further, this game was given to some teachers in government schools which having a separate special education classes.

However, providing the final game in a $\mathrm{CD}$ is limited to several special education centres and governmental schools. Therefore, to improve the accessibility for this special game, a blog was created and the games also are uploaded for free access: http://ictbasedspecialeducation.blogspot.com/

This project has been released in two packages under GNU General Public License (GPL) Version 3. One package consists of the games in a non editable format (includes only.swf files) targeting normal users of the product. Under the license, the users of that package have the freedom to share and distribute copies.

The second package consists of the games in editable format (includes both .swf files and .fla files) with the source code. It was released targeting the content developers. However, because of the GNU GPL license, they also have the freedom to share and distribute copies and an additional freedom to modify the games. By making the source code available, evolving the game content is expected with the support of the community, who willing to improve these kind of products for students with special needs. When distributing these packages for a fee or even free of charge, all the recipients distribute the same freedom because GNU GPL is a copyleft license.

\section{EVALUATION}

Evaluation was done after several discussions with special education teachers on how the activities should be arranged for this purpose. The evaluation process was organized into three main sections:
i. Pre test round
ii. Practice round
iii. Post test round

Further, with the guidance of special education teachers, the test game was created to cover up the colour, number and language skills.

When considering one game, it has many levels including activities which gradually increases the difficulty from level to level (Fig.5). If student is capable of doing one level correctly then he/she can move in to the next level.

However, if the student is not capable of completing it correctly, he/she would derive to the level itself to try out and complete it again. Each level has been included with restart button to start the game from beginning according to their preference.

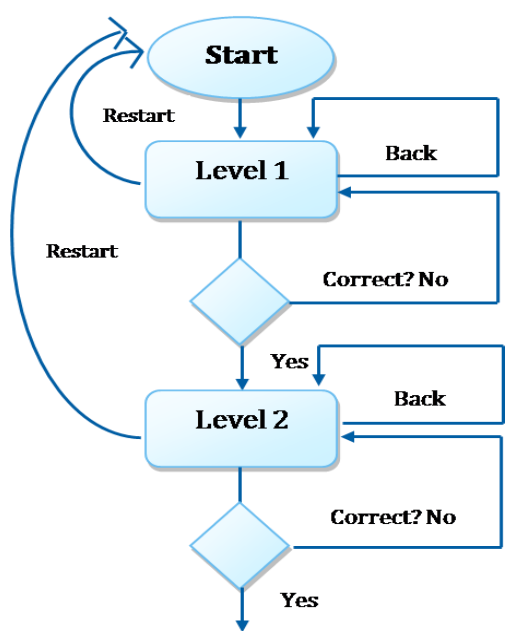

Fig. 5. Flow diagram of levels within a single game

The evaluation was done with a sample of 27 students covering both private special education centres and government schools. The sample was selected covering several disorders including Autism, Down syndrome and ADHD.

Initially the pre-test round started with colour game which has ten levels. According to the teachers, starting from colours is better for these children since they are very interested in colours. Therefore, primary colours, red, blue and yellow were considered at this stage and then their capabilities of distinguishing colours out of two to three colours was tested. Coloured, real world objects have been used in the last level to make them familiar with day to day objects. When a student completes the game, the time 
duration spent to complete is displayed in the interface (Figure 6).

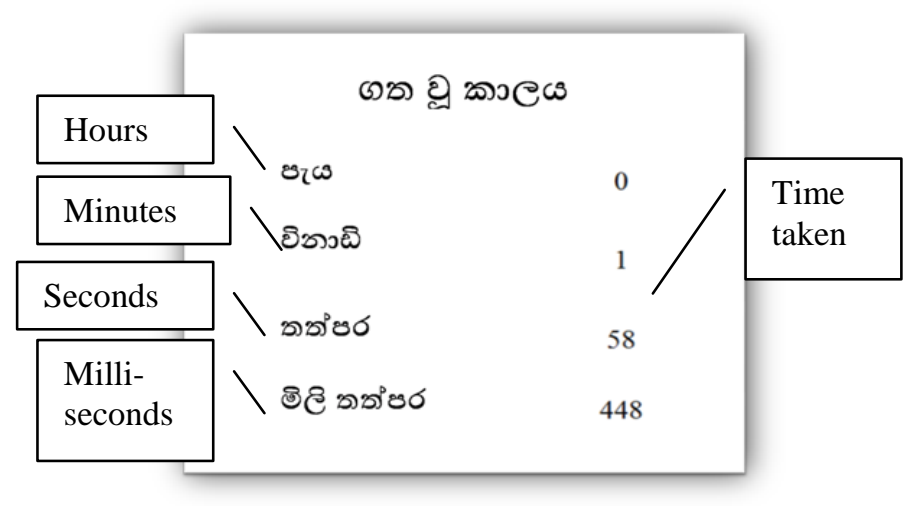

Fig. 6. Displaying time duration after completing a game

After completing the first round of pre-test with colour game, the students were engaged with number games. Even though ten levels were include in colour games, the umber pre-test game consists with only six levels because it was evident that having ten levels within one game is fatigue for them. The focus was on identifying their knowledge on numbers as one, two and three in primary level. Similar to the colour game, this game also consists of introducing numbers and examining students' knowledge in distinguishing two numbers. The language skills were evaluated as the last round of pre-test where the letter identification was tested for primary level students using three Sinhala letters, 'O', '๑' and ' 6 '.

Each student is allowed to do these pre test games individually and their capabilities were identified. Time taken to complete a game, number of mistakes made within the game and number of levels completed were considered when students play the game. In addition to those details some other details such as the type of disorder, age, duration of formal special education, computer accessibility were recorded. Further, some special comments were recorded on how they perform in individual games.

After the pre test round, the sample of students has practiced for a practice round, with the developed games for nearly a month and during that period each student got around 1 to 3 hours training depending on his/her acquiring ability.

Afterwards, the post-test stage was carried out to verify the improvement of these students. As done in the pre-test stage, the same order was carried out starting from colour and then number and language skills. Each student was individually examined and details were recorded including the time taken to complete the game, number of mistakes and number of levels they went through. According to the observations, these students were keen on playing games and it helps a lot to carry out the evaluation process properly.

Considerations in evaluation:

- Before starting pre test, a few time was given for students to practice mouse movements and clicks

- Mouse pointer had to be changed into a larger one (using Windows default mouse icons)

- More sounds were included into games for better attention

\section{ANALYSIS OF RESULTS}

In order to make decisions based on students' performance, a quantitative analysis was done with 35 student participants. However, all the students couldn't participate in the post-test. Thus, a comparison between the pre-test and post-test results was done based only on the 27 students. (In all the figures hereafter, "Std" stands for "Student" and accordingly "Std $i$ " stands for the $i^{\text {th }}$ student, where $i$ varies from 1 to 27.)

\section{A. Analysis based on Number of Levels Completed}

1) Colour Tests: According to the results of the pre-test and post-test, 2 students (7\%) have not proceeded beyond the level 0 while 13 students (48\%) have completed all 10 levels in both tests. Rest of the students (45\%) have completed even a single level in pre-test or post-test and generally increased their performance in post-test better than the pre-test. Therefore, it is clear that the improvement of colour skills is about $44 \%$ in terms of number of levels. However, no conclusion can be made with regard to those who completed same number of levels in both tests.

Figure 7 and Table I show the summary of these statistics.

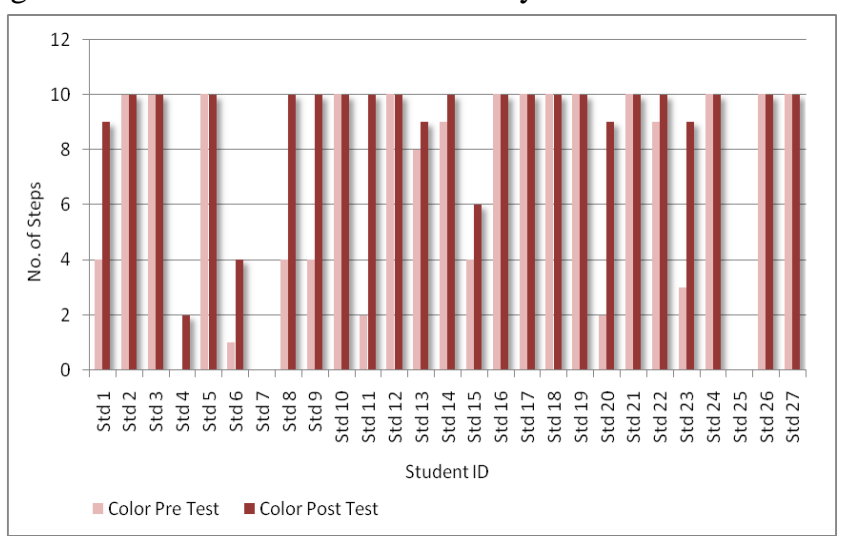

Fig. 7 Comparison of Number of Steps - Colour Skills

TABLE I

RESUlTS OF COLOUR GAMES WITH RESPECT TO THE NUMBER OF STEPS

\begin{tabular}{|l|c|c|}
\hline & $\begin{array}{c}\text { No. of Students } \\
\text { (Total = 27) }\end{array}$ & Percentage \\
\hline $\begin{array}{l}\text { Completed all steps in } \\
\text { both tests }\end{array}$ & 13 & $48.14 \%$ \\
\hline $\begin{array}{l}\text { Escalation in post test } \\
\text { than pre test }\end{array}$ & 12 & $44.44 \%$ \\
\hline No improvement in tests & 2 & $7.41 \%$ \\
\hline
\end{tabular}

2) Number Tests: Completed number of levels related to pre test and post test of number skills indicates an improvement in almost all the students while one student has not attempted even the first level in both tests. 15 students (56\%) have completed all 6 levels and 2 students $(7 \%)$ have done 5 levels in both tests. 8 students $(30 \%)$ have had an increase in the number of levels in the post test. Notably, one student $(4 \%)$ has ended up with a lesser number of levels in the post test.

See Figure 8 and Table II for the summary of the statistics. 


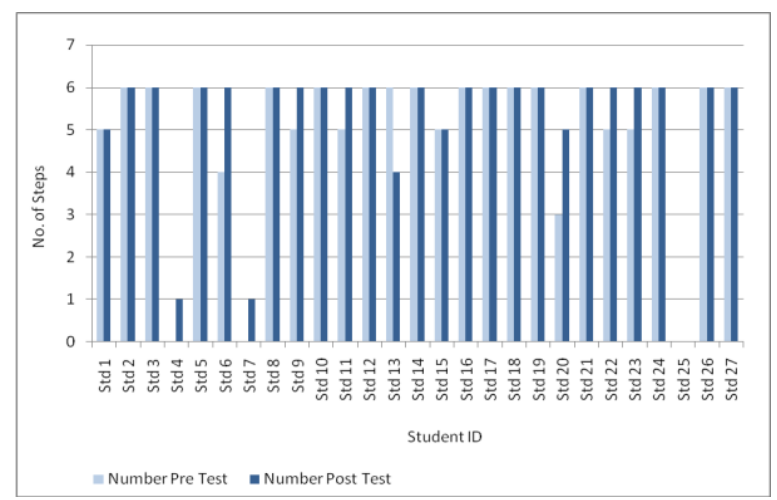

Fig. 8 Comparison of Number of Steps - Number Skills

TABLE II

RESUltS OF NUMBER GAMES WITH RESPECT TO THE NUMBER OF STEPS

\begin{tabular}{|l|c|c|}
\hline & $\begin{array}{c}\text { No. of Students } \\
\text { (Total = 27) }\end{array}$ & Percentage \\
\hline $\begin{array}{l}\text { Complete all steps in } \\
\text { both tests }\end{array}$ & 15 & $55.55 \%$ \\
\hline $\begin{array}{l}\text { Escalation in post test } \\
\text { than pre test }\end{array}$ & 8 & $29.62 \%$ \\
\hline $\begin{array}{l}\text { Complete same number } \\
\text { of steps in both test }\end{array}$ & 2 & $7.41 \%$ \\
\hline $\begin{array}{l}\text { Less number of steps in } \\
\text { post test than pre test }\end{array}$ & 1 & $3.70 \%$ \\
\hline
\end{tabular}

3) Language Tests: Total number of students participated for the language test was 25, since there were 2 students (Std 12 and Std 15) who are Tamil students and therefore, cannot understand Sinhala language. The improvement of students in language skills based on the number of levels is about $28 \%$ because, 7 students have completed more levels in post test than pre test. Number of students who did all 6 levels in both tests is $14(56 \%)$ and 3 students (12\%) have ended up with a lesser number of levels in post test while only one student has completed the same number of levels, however not all 6 levels in both tests.

These statistics are presented in table III and Figure 9 (where Std 12 and Std 15 have been removed).

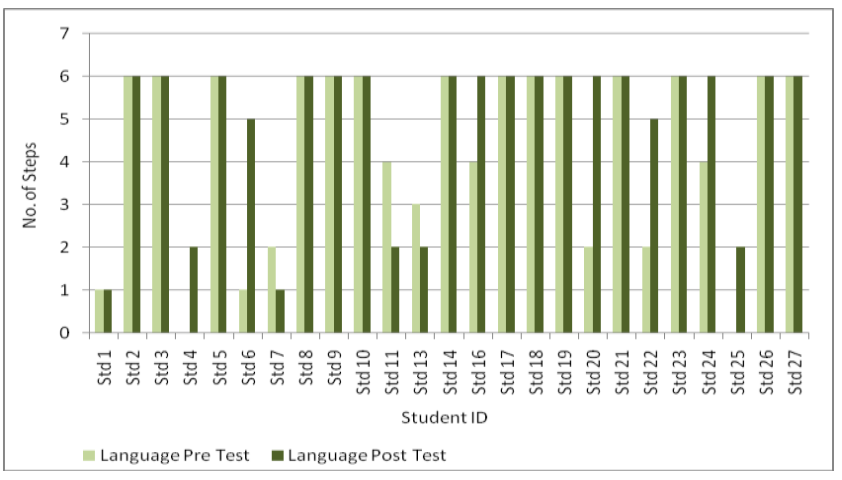

Fig. 9. Comparison of Number of Steps - Language Skills
TABLE III

RESUlts of LANGUAGE GAMES WITH RESPECT TO THE NuMBER OF STEPS

\begin{tabular}{|l|c|c|}
\hline & $\begin{array}{c}\text { No. of Students } \\
\text { (Total = 25) }\end{array}$ & Percentage \\
\hline $\begin{array}{l}\text { Complete all the steps } \\
\text { in both tests }\end{array}$ & 14 & $56 \%$ \\
\hline $\begin{array}{l}\text { Escalation in post test } \\
\text { than pre test }\end{array}$ & 7 & $28 \%$ \\
\hline $\begin{array}{l}\text { Complete same number } \\
\text { of steps in both test }\end{array}$ & 1 & $4 \%$ \\
\hline $\begin{array}{l}\text { Less number of steps in } \\
\text { post test than pre test }\end{array}$ & 3 & $12 \%$ \\
\hline
\end{tabular}

\section{B. Analysis Based on Average Time Taken per Level}

This analysis might not be practical if the comparison was done with the total time each student spent in both pre-test and post-test, because different students have left the game in different levels. Therefore, average time taken to complete a single level was calculated and a comparison was done between pre test and post test based on number of levels.

1) Colour Tests: Fig. 10 shows how the students have spent time in colour game, both pre-test and post-test. According to the graph, 26 students have taken less average time per level in the post test compared to the pre test. As a percentage, it is nearly $96 \%$. From those 27 students, only 1 student spent more average time in the post test.

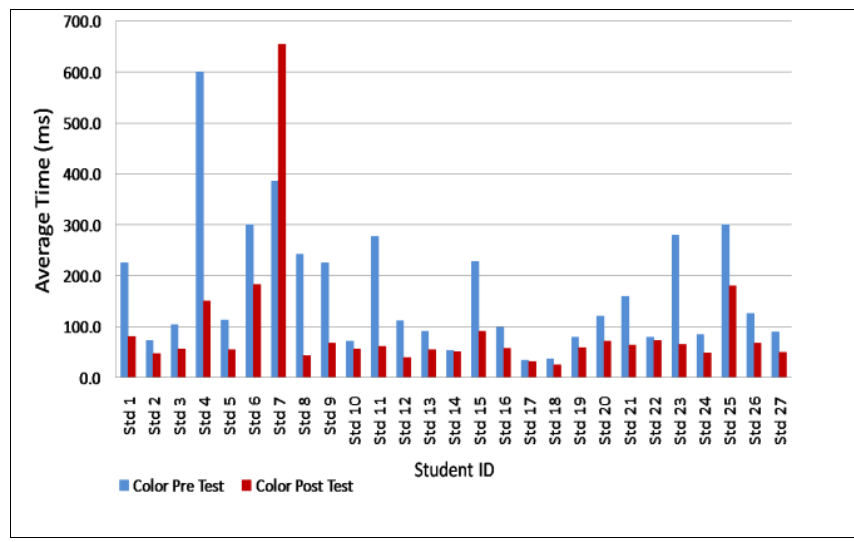

Fig. 10. Average time spent for a level by each student - Colour skills

The summary of above statistics is shown in table IV below.

TABLE IV

Results of Colour GAMES WITH RESPECt TO THE AvERAGE TIME

\begin{tabular}{|l|c|c|c|c|}
\hline \multirow{2}{*}{ Description } & \multicolumn{4}{|c|}{ Number of Students (27) } \\
\cline { 2 - 5 } & $\begin{array}{c}\text { Autism } \\
\text { (total 6) }\end{array}$ & $\begin{array}{c}\text { Down syndrome } \\
\text { (total 16) }\end{array}$ & $\begin{array}{c}\text { Other } \\
\text { (total 5) }\end{array}$ & Total \\
\hline Less average time in post test than pre test & 5 & 15 & 4 & 24 \\
\hline Same time in both pre test and post test & 1 & 1 & 0 & 2 \\
\hline More average time in post test than pre test & 0 & 0 & 1 & 1 \\
\hline
\end{tabular}

2) Number Tests: As shown in Fig. 11, among the sample of 27 students, 19 students (about 70\%) have taken less average time whereas the rest of the students (about 30\%) have taken a higher average time in post test than pre test. 
However, compared to the colour tests, the students have not performed well in number tests.

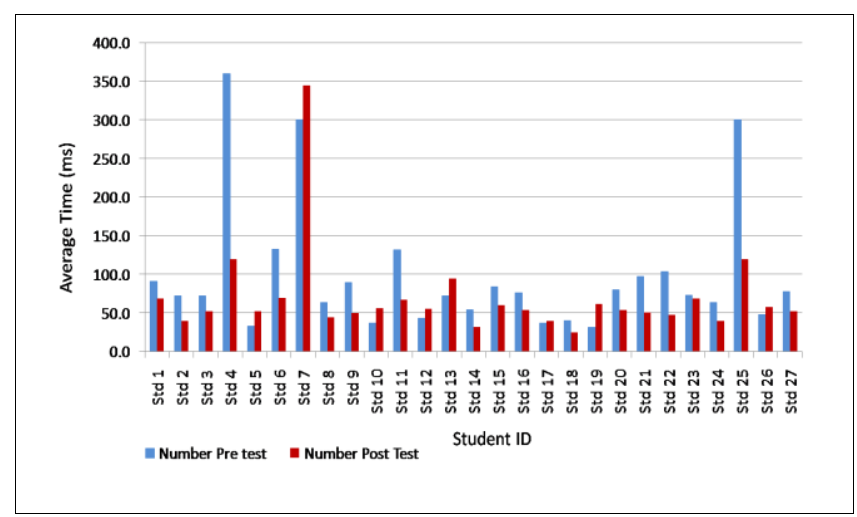

Fig. 11. Average time spent for a level by each student - Number skills

The summary of above statistics is shown in table $\mathrm{V}$ below.

TABLE V

RESUlts OF NuMBER GAMES WITH RESPECT TO THE AVERAGE TIME

\begin{tabular}{|l|c|c|c|c|}
\hline \multirow{2}{*}{ Description } & \multicolumn{4}{|c|}{ Number of Students (27) } \\
\cline { 2 - 5 } & $\begin{array}{c}\text { Autism } \\
\text { (total 6) }\end{array}$ & $\begin{array}{c}\text { Down syndrome } \\
\text { (total 16) }\end{array}$ & $\begin{array}{c}\text { Other } \\
\text { (total 5) }\end{array}$ & Total \\
\hline Less average time in post test than pre test & 5 & 11 & 3 & 19 \\
\hline Same time in both pre test and post test & 0 & 0 & 0 & 0 \\
\hline More average time in post test than pre test & 1 & 5 & 2 & 8 \\
\hline
\end{tabular}

\section{3) Language Tests:}

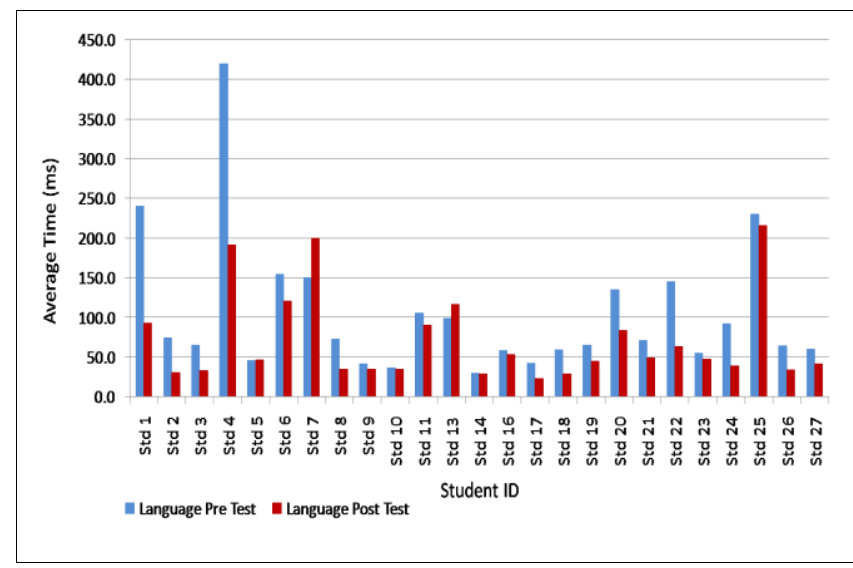

Fig. 12. Average time spent for a level by each student - Language skills

Among 25 students who participated in language tests, 22 students have taken less average time in post test indicating a percentage of around $88 \%$. Other 3 students, about $12 \%$ of the sample have taken a higher average time in post-test than the pre-test.

The summary of above statistics is shown in table VI below.
TABLE VI

RESUlts OF LANGUAGE GAMES WITH RESPECT TO THE AVERAGE TimE

\begin{tabular}{|l|c|c|c|c|}
\hline \multirow{2}{*}{ Description } & \multicolumn{4}{|c|}{ Number of Students (25) } \\
\cline { 2 - 6 } & $\begin{array}{c}\text { Autism } \\
\text { (total 6) }\end{array}$ & $\begin{array}{c}\text { Down syndrome } \\
\text { (total 15) }\end{array}$ & $\begin{array}{c}\text { Other } \\
\text { (total 4) }\end{array}$ & Total \\
\hline Less average time in post test than pre test & 6 & 13 & 3 & 22 \\
\hline Same time in both pre test and post test & 0 & 0 & 0 & 0 \\
\hline More average time in post test than pre test & 0 & 2 & 1 & 3 \\
\hline
\end{tabular}

\section{Analysis Based on Average Number of Mistakes}

Similar to the average time taken, it is unable to compare the number of mistakes done by students when comparing their pre-test with post-test since most of the students have completed different number of levels in those two tests. Therefore, the average number of mistakes per level was compared in this analysis.

1) Colour Tests: According to the results obtained in colour tests, one Autistic student has completed the post-test with a less average number of mistakes than the pre-test. In the category of Down syndrome, 10 students (about 63\%) have done fewer mistakes while other 6 students have completed the post test with a higher number of mistakes.

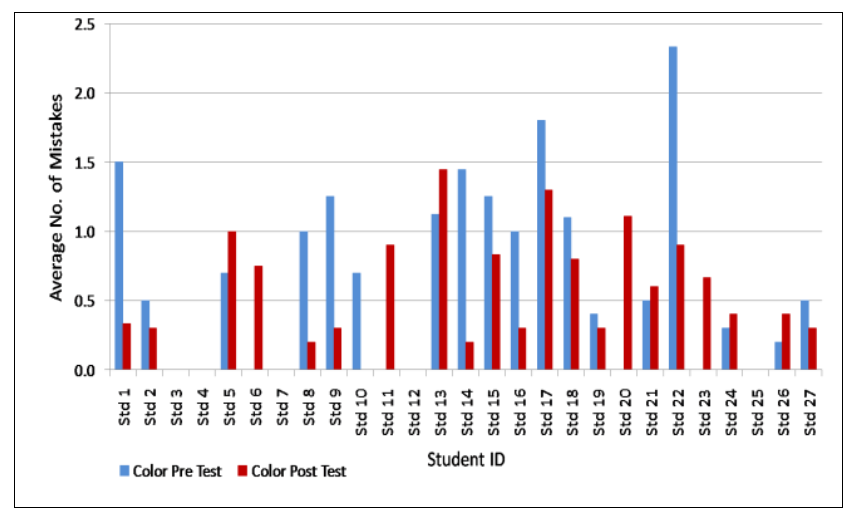

Fig. 13. Average number of mistakes per level-Colour tests

The summary of above statistics is shown in table VII.

TABLE VII

Average Number of Mistakes Done by Students in Colour Games

\begin{tabular}{|l|c|c|c|c|}
\hline \multirow{2}{*}{ Description } & \multicolumn{4}{|c|}{ Number of Students (27) } \\
\cline { 2 - 5 } & $\begin{array}{c}\text { Autism } \\
\text { (total 6) }\end{array}$ & $\begin{array}{c}\text { Down syndrome } \\
\text { (total 16) }\end{array}$ & $\begin{array}{c}\text { Other } \\
\text { (total 5) }\end{array}$ & Total \\
\hline $\begin{array}{l}\text { Less average number of mistakes in } \\
\text { post test than pre test }\end{array}$ & 1 & 10 & 2 & 13 \\
\hline $\begin{array}{l}\text { Same average number of mistakes in } \\
\text { both pre test and post test }\end{array}$ & 2 & 0 & 3 & 5 \\
\hline $\begin{array}{l}\text { More average number of mistakes in } \\
\text { post test than pre test }\end{array}$ & 3 & 6 & 0 & 9 \\
\hline
\end{tabular}

2) Number Tests: Out of 6 autistic students in the sample group, there were 3 students $(50 \%)$ have done post test with a less average number of mistakes than pre test. Further, 13 students with Down syndrome (about $81.25 \%$ ) and 1 student from the other category $(20 \%)$ have made less mistakes in post test than pre test. However, no interpretation can be 
made about those who have not done any mistake in both tests.

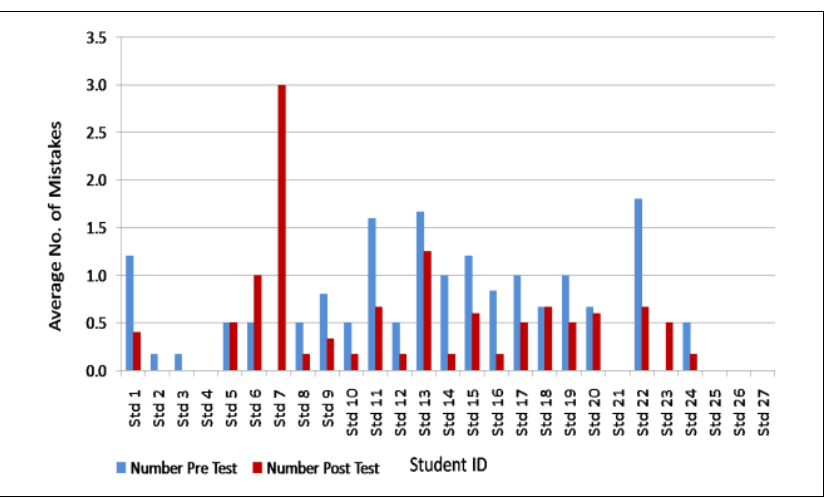

Fig. 14. Average number of mistakes per level - Number skills

The summary of above statistics is shown in table VIII.

TABLE VIII

Average Number of Mistakes Done by Students in Number Games

\begin{tabular}{|l|c|c|c|c|}
\hline \multirow{2}{*}{ Description } & \multicolumn{4}{|c|}{ Number of Students (27) } \\
\cline { 2 - 5 } & $\begin{array}{c}\text { Autism } \\
\text { (total 6) }\end{array}$ & $\begin{array}{c}\text { Down syndrome } \\
\text { (total 16) }\end{array}$ & $\begin{array}{c}\text { Other } \\
\text { (total 5) }\end{array}$ & Total \\
\hline $\begin{array}{l}\text { Less average number of mistakes } \\
\text { in post test than pre test }\end{array}$ & 3 & 13 & 1 & 17 \\
\hline No any mistake in both tests & 0 & 1 & 2 & 3 \\
\hline $\begin{array}{l}\text { Same average number of mistakes } \\
\text { in both pre test and post test }\end{array}$ & 2 & 1 & 1 & 4 \\
\hline $\begin{array}{l}\text { More average number of mistakes } \\
\text { in post test than pre test }\end{array}$ & 1 & 1 & 1 & 3 \\
\hline
\end{tabular}

3) Language Tests: Among 25 students (two students were not participated for language tests), average number of mistakes in post test has been reduced compared with pre test in language category for 3 students with autism (50\%), 10 students with Down syndrome (66.67\%) and 2 students from the other category $(50 \%)$.

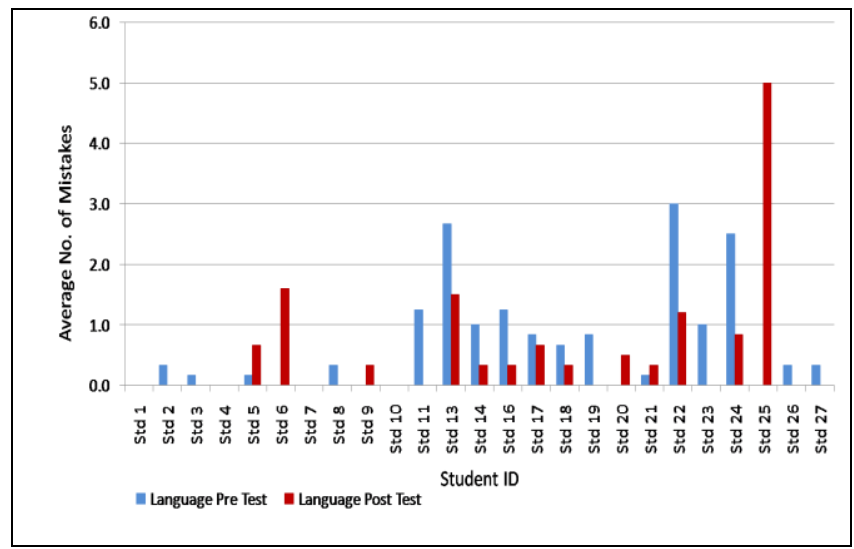

Fig. 15. Average number of mistakes per level - Language tests

The summary of above statistics is shown in table IX below.
TABLE IX

AVERAGE Number of Mistakes DONE By STUdents IN LANGUAGE GAMeS

\begin{tabular}{|l|c|c|c|c|}
\hline \multirow{2}{*}{ Description } & \multicolumn{3}{|c|}{ Number of Students (25) } \\
\cline { 2 - 5 } & $\begin{array}{c}\text { Autism } \\
\text { (total 6) }\end{array}$ & $\begin{array}{c}\text { Down } \\
\text { Syndrome } \\
\text { (total 15) }\end{array}$ & $\begin{array}{c}\text { Other } \\
\text { (total 4) }\end{array}$ & Total \\
\hline $\begin{array}{l}\text { Less average number of mistakes in post } \\
\text { test than pre test }\end{array}$ & 3 & 10 & 2 & 15 \\
\hline $\begin{array}{l}\text { Same average number of mistakes in both } \\
\text { pre test and post test }\end{array}$ & 0 & 2 & 2 & 4 \\
\hline $\begin{array}{l}\text { More average number of mistakes in post } \\
\text { test than pre test }\end{array}$ & 3 & 3 & 0 & 6 \\
\hline
\end{tabular}

\section{Analysis Based on Disorder Type}

Although the proposed solution is for all the categories of special educational needs, it is intended to test out whether there is a significant impact of that solution on any specific disorder. Therefore, the collected data set is analysed categorizing students according to the disorder as Down syndrome, Autism and other. Students who are having Cerebral Palsy and ADHD belong to "other" category.

In that sample of 27 students, there are 6 students with Autism, 16 students with Down Syndrome and 5 students are belonging to 'other' category. For the language test, out of the sample of 25 students, 6 students are with Autism, 15 students are with Down Syndrome and 4 students are belonging to 'other' category. The analysis is based on average number of mistakes done by a particular student per level and average time taken per level.

In order to get a clarified interpretation the derived diagrams have been divided into four parts as A, B, C and D as shown in below diagrams (Fig 16 to Fig 21). All the discussions are based on transitions of students' positions inbetween those four parts during pre test and post test. The transitions are as follows;

\begin{tabular}{|l|l|}
\hline A to B & Time has been increased while number of mistakes is high \\
\hline A to C & Taken time is high, number of mistakes has been reduced \\
\hline A to D & Number of mistakes has been reduced while time is less \\
\hline B to A & Time has been reduced while number of mistakes is high \\
\hline B to C & Number of mistakes has been reduced while time is high \\
\hline B to D & Both time and number of mistakes, have been reduced \\
\hline C to A & $\begin{array}{l}\text { Number of mistakes has been increased,taken time } \\
\text { reduced }\end{array}$ \\
\hline C to B & Number of mistakes has been increased while time is high \\
\hline C to D & Time has been reduced while number of mistakes is less \\
\hline D to A & Number of mistakes has been increased while time is less \\
\hline D to B & Both time and number of mistakes, have been increased \\
\hline D to C & Time has been increased while number of mistakes is less \\
\hline
\end{tabular}

\section{1) Colour Skills}

\section{Colour Pre Test}

According to figure 16, Std 4 and Std 7 can be identified as outliers compared to the rest of the sample. Std 4 has some disorders in his brain and as a result he lacks attention and eye contacts even with his parents and teachers.

Std 7 is with the disorder ADHD. ADHD students also lack attention. Therefore, interacting with a computer for a 
long time is a good practice for such students as they would be able to focus even though they cannot accomplish given activities.

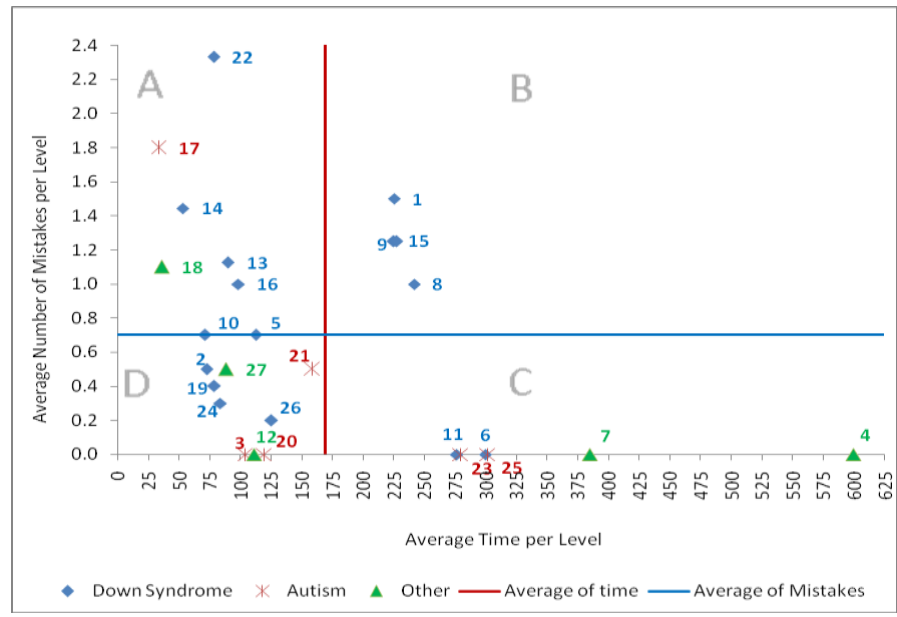

Fig. 16. Comparison of students based on disorder type - Colour pre test

\section{Colour Post Test}

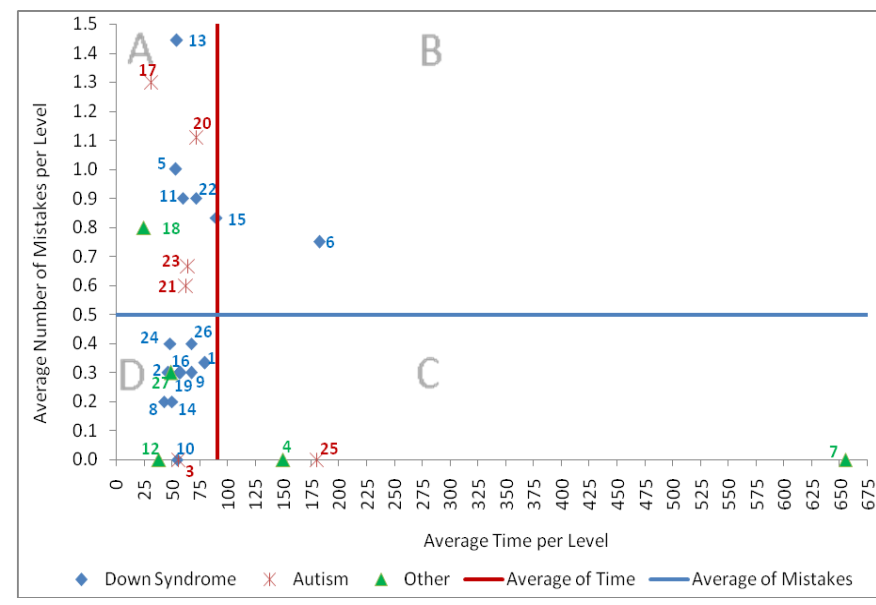

Fig. 17. Comparison of students based on disorder type - Colour post test

Table $\mathrm{X}$ consists of the data derived by analysing figure 16 and figure 17 . According to table X, nearly $43.75 \%$ of Down syndrome students have done colour post test better than colour pre test and nearly same percentage of Down syndrome students are in the same level in both pre test and post test. However, nearly $12.5 \%$ of students have not been improved compared to the rest of the sample of Down syndrome.

According to the statistics of Autistic students, $50 \%$ are in the same level in both tests and 50\% have not been improved when the whole sample is compared. When the "other" category is considered, all the students are in the same level, i.e. no visible improvements.

The summary derived through the comparison of colour tests is shown in table $\mathrm{X}$.
TABLE X

SUMMARY OF DATA IN FIG. 16 AND FIG. 17

\begin{tabular}{|c|c|c|c|c|c|c|c|}
\hline \multirow{2}{*}{$\begin{array}{l}\text { Color } \\
\text { Skills }\end{array}$} & \multirow{2}{*}{$\begin{array}{c}\text { Transition of the } \\
\text { position in } \\
\text { diagram (Pre } \\
\text { test to Post test) }\end{array}$} & \multicolumn{2}{|c|}{\begin{tabular}{|c|}
$\begin{array}{c}\text { Down Syndrome } \\
\text { (Total = 16) }\end{array}$ \\
\end{tabular}} & \multicolumn{2}{|c|}{$\begin{array}{c}\text { Autism } \\
\text { (Total }=6)\end{array}$} & \multicolumn{2}{|c|}{$\begin{array}{c}\text { Other } \\
(\text { Total = 5) }\end{array}$} \\
\hline & & \begin{tabular}{|c|} 
Studen \\
$\mathrm{t}$ ID
\end{tabular} & $\%$ & \begin{tabular}{|l|} 
Student \\
ID
\end{tabular} & $\%$ & $\begin{array}{l}\text { Student } \\
\text { ID }\end{array}$ & $\%$ \\
\hline \multirow{6}{*}{ improved } & A to $D$ & $\begin{array}{l}\text { Std 14, } \\
\text { Std 16 }\end{array}$ & $12.50 \%$ & & & & \\
\hline & $\mathrm{B}$ to $\mathrm{A}$ & \begin{tabular}{|l|} 
Std 15 \\
\end{tabular} & $6.25 \%$ & & & & \\
\hline & $\mathrm{B}$ to $\mathrm{C}$ & & & & & & \\
\hline & B to D & $\begin{array}{l}\text { Std 1, } \\
\text { Std 8, } \\
\text { Std 9 }\end{array}$ & $18.75 \%$ & & & & \\
\hline & $\mathrm{C}$ to $\mathrm{D}$ & Std 6 & $6.25 \%$ & & & & \\
\hline & Total & & $43.75 \%$ & & & & \\
\hline & & & & & & & \\
\hline \multirow{4}{*}{ Neutral } & Same (D to D) & $\begin{array}{l}\text { Std 2, } \\
\text { Std 10, } \\
\text { Std 19, } \\
\text { Std 24, } \\
\text { Std 26, } \\
\end{array}$ & $31.25 \%$ & $\begin{array}{l}\text { Std 3, } \\
\text { Std 17, } \\
\text { Std 25 }\end{array}$ & $50.00 \%$ & $\begin{array}{l}\text { Std 12, } \\
\text { Std 27 }\end{array}$ & $40 \%$ \\
\hline & Same (A to A) & $\begin{array}{l}\text { Std 13, } \\
\text { Std 22 } \\
\end{array}$ & $12.50 \%$ & & & Std 18 & $20 \%$ \\
\hline & Same (C to C) & & & & & $\begin{array}{l}\text { Std 4, } \\
\text { Std 7 }\end{array}$ & $40 \%$ \\
\hline & Total & & $43.75 \%$ & & $50.00 \%$ & & $100 \%$ \\
\hline \multirow{3}{*}{$\begin{array}{l}\text { Not } \\
\text { improved }\end{array}$} & $\mathrm{C}$ to $\mathrm{A}$ & \begin{tabular}{|l|} 
Std 11 \\
\end{tabular} & $6.25 \%$ & Std 23 & $16.66 \%$ & & \\
\hline & $\mathrm{D}$ to $\mathrm{A}$ & Std 5 & $6.25 \%$ & $\begin{array}{l}\text { Std 20, } \\
\text { Std 21 }\end{array}$ & $33.33 \%$ & & \\
\hline & Total & & $12.50 \%$ & & $49.99 \%$ & & \\
\hline
\end{tabular}

\section{2) Number Skills}

The students' performance on number skills in terms of average time spent and average number of mistakes per level is depicted in Figure 18 and Figure 19.

\section{Number Pre Test}

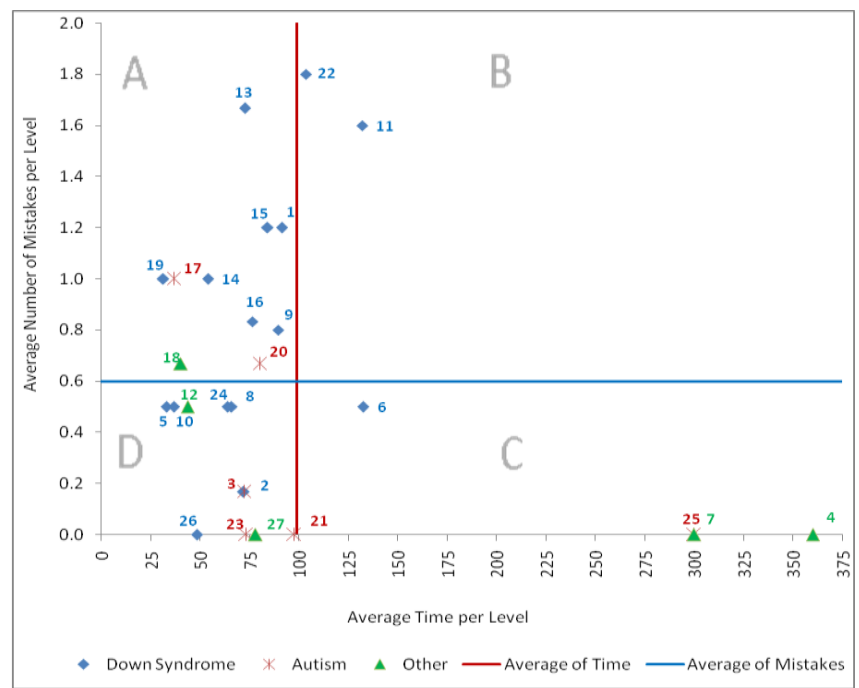

Fig. 18. Comparison of students based on disorder type - Number pre test

\section{Number Post Test}

The summary of figure 18 and figure 19 is included in table XI and it depicts the details about number skills of sample students. Among 16 of the Down syndrome students, nearly $44 \%$ have done post test better than pre test in the total sample. $44 \%$ of students are in the same level in both tests while $13 \%$ of students have not been improved.

Approximately $17 \%$ of Autistic students have done post test better than pre test. About $83 \%$ of students are in the same level in both tests. In "other" category, $80 \%$ of the students are in the same level compared to the whole sample 
while $20 \%$ of the students have ended up with less performance in the post test than the pre test.

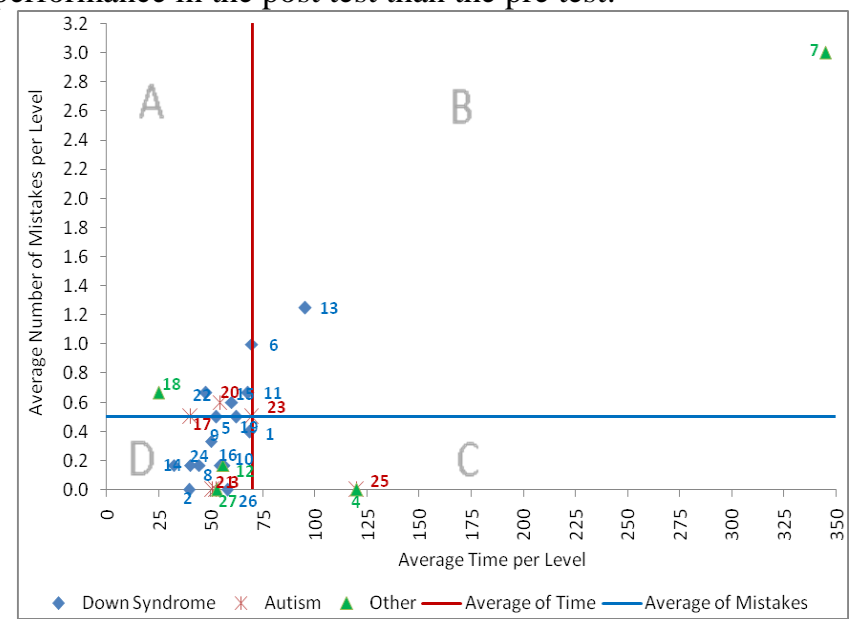

Fig. 19. Comparison of students based on disorder type - Number post test

TABLE XI

SUMMARY OF DATA IN FIG. 18 AND FIG. 19

\begin{tabular}{|c|c|c|c|c|c|c|c|}
\hline \multirow[t]{2}{*}{$\begin{array}{c}\text { Number } \\
\text { Skills }\end{array}$} & \multirow{2}{*}{$\begin{array}{c}\text { Transition of } \\
\text { the position in } \\
\text { diagram (Pre } \\
\text { test to Post } \\
\text { test) }\end{array}$} & \multicolumn{2}{|c|}{$\begin{array}{c}\text { Down Syndrome } \\
(\text { Total = 16) }\end{array}$} & \multicolumn{2}{|c|}{$\begin{array}{c}\text { Autism } \\
(\text { Total }=6)\end{array}$} & \multicolumn{2}{|c|}{$\begin{array}{c}\text { Other } \\
(\text { Total }=5)\end{array}$} \\
\hline & & $\begin{array}{l}\text { Student } \\
\text { ID }\end{array}$ & $\%$ & $\begin{array}{l}\text { Student } \\
\text { ID }\end{array}$ & $\%$ & $\begin{array}{c}\text { Student } \\
\text { ID }\end{array}$ & $\%$ \\
\hline \multirow[t]{3}{*}{ improved } & A to $D$ & $\begin{array}{l}\text { Std 1, } \\
\text { Std } 9, \\
\text { Std } 14, \\
\text { Std } 16, \\
\text { Std } 19\end{array}$ & $31.25 \%$ & Std 17 & $16.66 \%$ & & \\
\hline & $\mathrm{B}$ to $\mathrm{A}$ & $\begin{array}{l}\text { Std 11, } \\
\text { Std 22 }\end{array}$ & $12.50 \%$ & & & & \\
\hline & Total & & $43.75 \%$ & & $16.66 \%$ & & \\
\hline \multirow[t]{4}{*}{ Neutral } & Same (D to D) & $\begin{array}{l}\text { Std 2, } \\
\text { Std } 5 \\
\text { Std } 8, \\
\text { Std } 10, \\
\text { Std } 24, \\
\text { Std 26, }\end{array}$ & $37.50 \%$ & $\begin{array}{l}\text { Std 3, } \\
\text { Std 21, } \\
\text { Std 23, } \\
\text { Std 25 }\end{array}$ & $66.66 \%$ & $\begin{array}{l}\text { Std 12, } \\
\text { Std 27 }\end{array}$ & $40 \%$ \\
\hline & Same (A to $A$ ) & Std 15 & $6.25 \%$ & Std 20 & $16.66 \%$ & Std 18 & $20 \%$ \\
\hline & Same (C to C) & & & & & Std 4 & $20 \%$ \\
\hline & Total & & $43.75 \%$ & & $83.33 \%$ & & $80 \%$ \\
\hline \multirow{4}{*}{$\begin{array}{l}\text { Not } \\
\text { improved }\end{array}$} & $A$ to $B$ & Std 13 & $6.25 \%$ & & & & \\
\hline & $\mathrm{C}$ to $\mathrm{A}$ & Std 6 & $6.25 \%$ & & & & \\
\hline & $\mathrm{C}$ to $\mathrm{B}$ & & & & & \begin{tabular}{|l|} 
Std 7 \\
\end{tabular} & $20 \%$ \\
\hline & Total & & $12.50 \%$ & & & & $20 \%$ \\
\hline
\end{tabular}

\section{3) Language Skills}

\section{Language Pre Test}

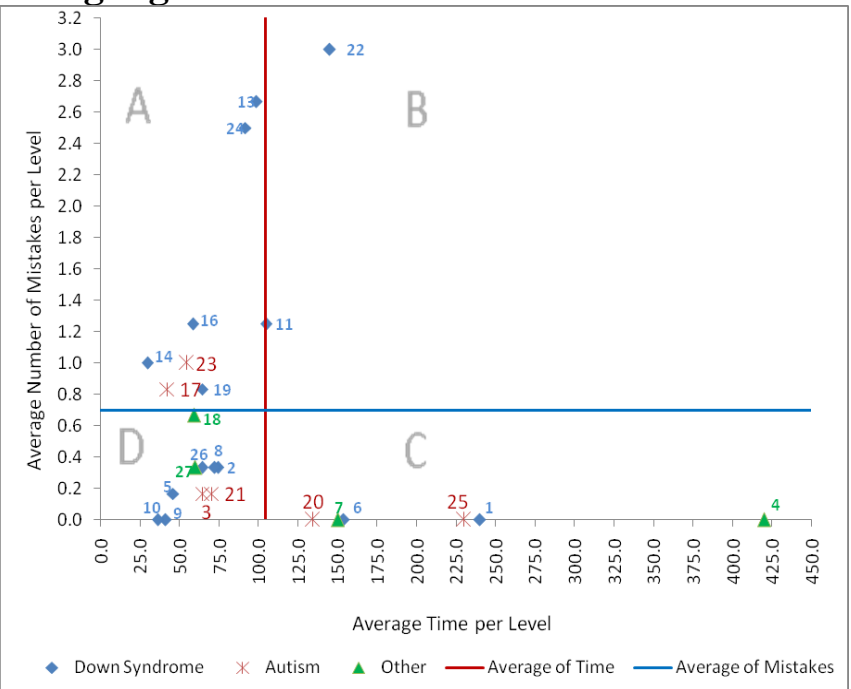

Fig. 20. Comparison of students based on disorder type - Language pre test

\section{Language Post Test}

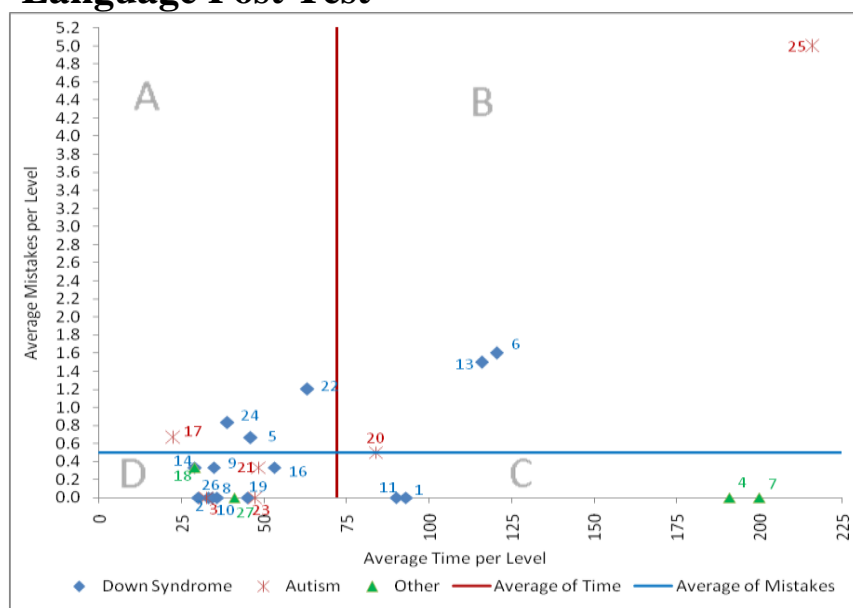

Fig. 21. Comparison of students based on disorder type - Language post test

The data about language skills included in Table XII has been derived from figure 20 and figure 21 . According to the statistics of Down syndrome students, about $33 \%$ have done post test better than pre test. About $47 \%$ of students are in same level in both tests and $20 \%$ of students have ended up with less performance in post test than pre test compared to the whole sample.

According to the pre test and post test results of Autistic students, improvement rate is about $17 \%$. However, all the students in the "other" category have maintained the same level in both tests compared to the whole sample.

TABLE XII

SUMMARY OF DATA IN FIG. 20 AND FIG. 21

\begin{tabular}{|c|c|c|c|c|c|c|c|}
\hline \multirow[t]{2}{*}{$\begin{array}{l}\text { Language } \\
\text { Skills }\end{array}$} & \multirow{2}{*}{$\begin{array}{l}\text { Transition of } \\
\text { the position in } \\
\text { scatter } \\
\text { diagram (Pre } \\
\text { test to Post } \\
\text { test) }\end{array}$} & \multicolumn{2}{|c|}{$\begin{array}{c}\text { Down Syndrome } \\
(\text { Total = 15) }\end{array}$} & \multicolumn{2}{|c|}{$\begin{array}{c}\text { Autism } \\
(\text { Total }=6)\end{array}$} & \multicolumn{2}{|c|}{$\begin{array}{c}\text { Other } \\
(\text { Total }=4)\end{array}$} \\
\hline & & $\begin{array}{l}\text { Student } \\
\text { ID }\end{array}$ & $\%$ & $\begin{array}{l}\text { Student } \\
\text { ID }\end{array}$ & $\%$ & $\begin{array}{l}\text { Student } \\
\text { ID }\end{array}$ & $\%$ \\
\hline \multirow[t]{4}{*}{ improved } & A to $D$ & $\begin{array}{l}\text { Std 14, } \\
\text { Std 16, } \\
\text { Std 19 }\end{array}$ & $20.00 \%$ & Std 23 & $16.66 \%$ & & \\
\hline & $\mathrm{B}$ to $\mathrm{A}$ & Std 22 & $6.66 \%$ & & & & \\
\hline & $\mathrm{B}$ to $\mathrm{C}$ & Std 11 & $6.66 \%$ & & & & \\
\hline & Total & & $33.33 \%$ & & $16.66 \%$ & & \\
\hline \multirow{5}{*}{ Neutral } & & & & & & & \\
\hline & Same (D to D) & $\begin{array}{l}\text { Std 2, } \\
\text { Std } 8, \\
\text { Std } 9, \\
\text { Std 10, } \\
\text { Std 26 }\end{array}$ & $33.33 \%$ & $\begin{array}{l}\text { Std 3, } \\
\text { Std } 21\end{array}$ & $33.33 \%$ & $\begin{array}{l}\text { Std 18, } \\
\text { Std } 27\end{array}$ & $50 \%$ \\
\hline & Same (A to A) & Std 24 & $6.66 \%$ & Std 17 & $16.66 \%$ & & \\
\hline & Same (C to C) & Std 1 & $6.66 \%$ & Std 20 & $16.66 \%$ & $\begin{array}{l}\text { Std 4, } \\
\text { Std 7 }\end{array}$ & $50 \%$ \\
\hline & Total & & $46.66 \%$ & & $66.66 \%$ & & $100 \%$ \\
\hline \multirow{4}{*}{$\begin{array}{l}\text { Not } \\
\text { improved }\end{array}$} & A to $B$ & Std 13 & $6.66 \%$ & & & & \\
\hline & $\mathrm{C}$ to $\mathrm{B}$ & Std 6 & $6.66 \%$ & Std 25 & $16.66 \%$ & & \\
\hline & $\mathrm{D}$ to $\mathrm{A}$ & Std 5 & $6.66 \%$ & & & & \\
\hline & Total & & $19.98 \%$ & & $16.66 \%$ & & \\
\hline
\end{tabular}

\section{DISCUSSION}

There is a list of significant findings that identified by analysing the diagrams, tables and information discussed in 'Analysis of Results' chapter. When comparing the 'average time taken to complete a single level in the game' and 
'number of mistakes per level', it is clear that the performance improvement rates are higher in terms of average time. That means the efficiency of students has been improved rather than the effectiveness.

- The improvement rate of students who have computers at home (about $85 \%$ ) is higher than those who do not have computers at home $(50 \%)$. Therefore, the practice of using a computer at home also may have an effect on students' performance improvement.

- When the students who do not have computers at home are considered, students with Down syndrome have improved more than the Autistic students.

- Female students have shown a better improvement than male students in both number and language skills activities.

- However, both genders have shown equal improvements in colour skills.

\section{CONCLUSION}

Even though the society is in the knowledge era, unfortunately there is no opportunity for the students with special needs to take the advantage of ICT based education. Although most of the countries have carried out many researches and projects with regards to how ICT can be utilized addressing this issue, in Sri Lankan context, it is a stranger. As a result, this research was carried out in order to study the potential of ICT usage at special education in Sri Lanka and analyse the effect of ICT based education those students' performance. In this study it was focused on a critical evaluation on students' performance using some computer based educational games specially developed for students with special educational needs, covering the three main subject areas: Colour, Number and Language. Those games were developed under the guidance of consultants and teachers in special education. Since this is for a special category of students, many design considerations have to be considered.

In order to evaluate the improvement of performance, two tests were carried out as pre test and post test. In addition to that, the sample of students was given a one-month training using designed games in between pre test and post test. A quantitative analysis was done based on the number of levels a particular student completed, average time taken per level and average number of mistakes made per level. However, it is impractical to have a qualitative analysis in this kind of a research area because, it is impossible to get feedbacks from students with special needs about the proposed solution. However, throughout the research, it was evident that these students are very interested in their lessons with the help of these applications.

According to the analysis on the number of average mistakes per level, about $48 \%$ in colour skills $63 \%$ in number and $60 \%$ in language have made less number of mistakes per level in both tests. Therefore, these rates indicate improvement of performance ultimately.

Thus, it is evident that usage of ICT in a game based approach as learning aids has a positive impact on the improvement of the performance of students with special needs.

However, it will not be able to alter the traditional special education entirely from ICT based special education. The proposed solution would be an aid for sharpening the knowledge of students with special needs further.

\section{FUTURE WORK}

Repetition is a vital factor when it comes to students with special needs. Although the quantitative analysis gives positive results while indicating a considerable improvement of the performance of these students, there can be a significant improvement if they are being given some more practice within the school time as well as at home. Therefore, the significance of this game-based learning approach will have a higher success rate through continuous training.

Since some of the activities developed under this research are based on mouse clicking and dragging, handling the computer mouse is also a vital skill. It was somewhat problematic for these students and there were some students who struggled with the mouse, specially the children with Cerebral Palsy disorder. Those students would benefit a lot from some hardware solutions such as touch screens as it would be much easier for them involve in the activities.

The students get distracted when they see a pop up menu as they usually tend to click the right mouse button instead of the left mouse button. It was also noticed that most of the students are interested in using the wheel of the mouse. As they lose their concentration, it is better to have a specially designed device for them with a single button, without a wheel.

If these games could be optimized as apps for mobile devices such as i-pads, the students would be happier to use them than computers. Further, it will help to break the monotony of these games and create more interest on students.

\section{ACKNOWLEDGEMENT}

We extend our gratitude to all the teachers at Chithra Lane Special Education Centre and Mahawila Junior School, Panadura for giving us valuable domain knowledge and allowing us to work with special needs students. Further, we appreciate the great support of Dr. Sudath Damsinghe and the staff of Daddys Lanka Autism Centre.

\section{REFERENCES}

[1] M. A. G. Kemp, M. A. S. Smith and J. Segal (2012, January). Learning Disabilities in Children. Web. Available: http://www.helpguide.org/mental/learning disabilities.htm

[2] L. Silbert (2012). List of Learning Disabilities. Web. Available: http://drlindasblog.com/list-of-learning-disabilities/

[3] Wijeya Newspapers (2011, May 15). Mediscene. Magazine. Available: http://sundaytimes.1k/110515/MediScene/mediscene 1.html

[4] S. Kuruppuarachchi, "Status of School Library Development in Sri Lanka," Sri Lanka Journal of Librarianship \& Information Management, vol. 1, no.1, pp 25-30.

[5] R. P. Mahaliyanaarachchi, K. P. Perera and W. P. Perera, "Subject Review Report," Department of Special Needs Education, Open University of Sri Lanka, pp. 1-13.

[6] K.Staikou, S.Avropoulou and C. Karagiannidis, "Development of educational software for teaching daily life skills to students in the spectrum of autism", pp.105-108, 2008.

[7] D . Mioduser, H . Tur-Kaspa and I. Leitner, "The learning value of computer based instruction of early reading skills," Computer Assisted Learning, vol. 16, pp. 54-63, 2000.

[8] G.R.Hayes, "Understanding educational technology through special education and autism", University of California, Irvine, 2007. 
[9] A . Luneski, I. Evdokimos, M. Hitoglou, and P.D. Bamidis, "Affective Computer-Aided Learning for Autistic Children," 1st Workshop on Child- Computer and Interaction, 2008.

[10] Y. Liu, A. Cornish, J. Clegg, "ICT and Special Educational Needs: Using Meta-synthesis for Bridging the Multifaceted Divide," 18-25, 2007.

[11] M. Silva, C. Simoes, D. Gonçalves, T. Guerreiro H. Silva, F. Botelho, "TROCAS: Communication Skills Development in Children with Autism Spectrum Disorders via ICT," 645-648, 2011.

[12] G. R. Hayes, "Understanding educational technology through special education and autism," University of California, Irvine, 2007.

[13] M. Thomson, "Using ICT to support Dyslexia in the secondary school," Dyslexia, Britain, 2007.

[14] J.M.Ribeiro, A.Moreira and A.M.P.Almeida, "Preparing special education frontline professionals for a new teaching experience", $E$ Learning Papers, issn 1887-1542, pp. 1-10,2009.

[15] Becta, "What the research says about ICT supporting special educational needs and inclusion" 2003.

[16] M. Saridaki, L and C. Mourlas, "Fingers on the screen: game based learning for students with intellectual disabilities", E-Learning Papers, pp. 1-4, 2011.

[17] C. Hayford, Leslie, Lynch, Paul, "ICT Based Solutions for Special Educational Needs in Ghana," 2003.

[18] Wettasinghe, Marissa, M. Hasan, "Investigating the efficacy of the use of ICT for slow learners: Case studies in Singapore Primary Schools," in Proceedings of the ICL Conference 2007, Villach, Austria, 1-11, 2007.

[19] A.Protopsaltis, L.Pannese, D.Pappa, and S.Hetzner, "Serious games and formal and informal learning" E-Learning Papers, ISSN: 1887-1542, pp. 1-8, 2011.

[20] S. Arnab, R. Berta, J. Earp, S. de Freitas, M. Popescu, M. Romero, I. Stanescu, and M. Usart, "Framing the Adoption of Serious Games in Formal Education," Electronic Journal of e-Learning, vol. 10, no. 2, 2012.

[21] C. S. Lanyi, D. J. Brown, P. Standen, J. Lewis, V. Butkute, and D. Drozdik, "GOET European project of serious games for students with intellectual disability," in Cognitive Infocommunications (CogInfoCom), 2011 2nd International Conference on, 2011, pp. 1-6.

[22] P.Biswas, "Simulating HCI for special seeds", Sigaccess Newsletter, vol. 1, no. 89, pp. 7-10, 2007.

[23] M.P.Wachowiak, R.W.Smolikova and G.D.Fryia, "Practical considerations in human-computer interaction for e-learning", International Journal of Information Studies, vol. 2, no. 1, pp. 60-70, 2010.

[24] M. P. Wachowiak, R. W. Smolikova, G.D. Fryia, "Practical considerations in human-computer interaction for e-learning," International Journal of Information Studies, Vol. 2, no. 1, 60-70, 2010.

[25] L. Florian, "Uses of technology that support pupils with special educational needs", 2003.

[26] C.S.Lanyi, Z.Geiszt, P.Karolyi, A.Tilinger and V.Magyar, "Virtual reality in special needs early education", The International Journal of Virtual Reality, vol. 5, no. 4, pp. 55-67. 2006.

[27] Konstantinidis , I. Evdokimos, Luneski, Andrej, Frantzidis, A Christos, Nikolaidou, Maria, H. Antoniadou, Magda and Bamidis, D. Panagiotis, "Information and communication technologies (ICT) for enhanced education of children with autism spectrum disorders", The Journal on Information Technology in Healthcare, vol 7 (5), pp. 284-292, 2009.

[28] A.Aspinall and R.Hegarty "ICT for adults with learning disabilities: an organization wide audit", British Journal of Educational Technology, vol.32, no. 3, pp. 365-372

[29] C. L. M. Santarosa, O. L. Basso, "Eduquito: virtual environment for digital inclusion of people with special educational needs," Journal of Universal Computer Science, Vol. 15, no. 7, 1496-1507, 2009.

[30] M. P. Wachowiak, R. W. Smolikova, G.D. Fryia, "Practical considerations in human-computer interaction for e-learning," International Journal of Information Studies, Vol. 2, no. 1, 60-70, 2010. 